\title{
Surface alloying of pure iron by molybdenum and tin by a continuous wave $\mathrm{CO}_{2}$ laser
}

\author{
I S BATRA, K BHANUMURTHY, S K KHERA, A K SINHA*, \\ A R BISWAS*, V I TITOV ${ }^{\dagger}, M$ B IGNATIEV ${ }^{\dagger}$ and A UGLOV ${ }^{\dagger}$ \\ Metallurgy Division and *Atomic Fuels Division, Bhabha Atomic Research Centre, \\ Bombay 400085 , India \\ 'Baikov Institute of Metallurgy, 49 Leninsky Prospect, Moscow, Russia \\ MS received 28 January 1993; refred 8 June 1993
}

\begin{abstract}
It is now well established that considerable improvement in the mechanical/ chemical properties of near surface regions of materials can be achieved by the process of laser surface alloying. The change in chemistry at the surface is attained through the process of melting and mixing of a predeposited coating and a thin layer of the substrate. Rapid solidification of this molten region at the surface then results in the deveiopment of very interesting microstructural features. In the present work, an attempt was made to surface alloy pure iron by molybdenum and/or tin by using a continuous wave $\mathrm{CO}_{2}$ laser. Morphology of the resulting microstructural features was examined by optical as well as scanning electron microscopy and the compositional details were determined using an electron probe microanalyser. Microhardness measurements were carried out as a function of depth from the laser-treated surface. This paper discusses the results of these investigations and delineates the roles of the various parameters on the chemistry and microstructure of the surface alloys formed as a result of laser treatment.
\end{abstract}

Keywords. Surface alloying; laser processing; solidification; microstructures.

\section{Introduction}

Being intense and controllable heat sources, lasers are used (Ready 1978; Metzbower 1981 ) in a variety of ways to process materials of different kinds. Applications in metal fabrication include welding, drilling and cutting, and treatments to alter the chemistry and properties of surfaces. By manipulating the laser power density and the time of interaction of the laser beam with an appropriately coated work-piece, it is possible (Chande and Majumdar 1979; Nurminen and Smith 1979; Crolet 1990) to achieve a surface chemistry that would have an improved resistance to wear, fatigue and corrosion failures. The change in chemistry at the surface is obviously obtained (Rykalin et al 1988) through the process of melting and mixing the coat and a thin layer of the substrate. Whereas the extent (depth) of melting (and, therefore, the extent of dilution) depends upon the laser power density and the interaction time, the extent of mixing depends on the nature of the elements to be alloyed, the convection currents (Anthony and Clinen 1977) set by the composition and temperature dependent surface tension gradients in the melt-pool, and the flow (Rykalin et al 1988) of the melt from the leading edge of the pool to its trailing edge because of the reactive back pressure of the evaporated mass. Competing with this mixing in the melt-pool is the process of solidification (Boettinger 1982; Flemings and Shiohara 1984; Jones 1984). It involves (Mehrabian 1982) the development of new microstructures through a complex interplay between the temperature gradient, the velocity of the solidification front, and the cooling rate. The nature of the microstructure at any location in the pool is determined 
by the ratio of the temperature gradient to the velocity of the solidification front obtained at that location, and the scale of the microstructure at any location is determined by the cooling rate which is characterized, in turn, by the product of the temperature gradient and the velocity of the solidification front at that location. Also associated with this process of solidification is the possible partitioning (Sarreal and Abbaschian 1986) of the elements. Since cooling involved in the process is rather rapid, chances of homogeneous nucleation in the liquid leading to the formation of metastable phases and a disturbance to the above trends of solidification cannot be ruled out. After solidification, also inevitable are the solid state transformations which are governed (Porter and Easterling 1981; Molian et al 1982) by the cooling rate obtained at any location and the time-temperature transformation characteristics appropriate to the composition at that location. Generally, in any laser surface alloying treatment, very complex (but interesting) microstructural features develop because of the above reasons. Also, sometimes physical defects like cracks develop in the alloyed layer, or the substrate just below it if the differential coefficients of thermal contraction of the new alloy at the surface and the base are large enough to generate quenching strains beyond their ductility limits. It is also possible (Rykalin et al 1988) that a non-uniform distribution of the alloying elements in the recast surface may give rise to local stresses leading to the formation of cavities in the surface layer, or to splitting between the surface layer and the base metal below it.

This study aims at examining the effects of various parameters like the energy density of the beam, interaction time of the beam with the work-piece and the thickness and composition of the surface coating on the chemistry and microstructure of the surface alloy formed as a result of the treatment by a continuous wave $(\mathrm{CW}) \mathrm{CO}_{2}$ laser.

\section{Experimental}

In the present experiments, pure iron was alloyed with either molybdenum or tin, or their different combinations. Powder of molybdenum or tin or a mixture of the two powders was laid on the surface of small pieces of Armco iron. The surfaces thus coated with the powders were laser-treated (to produce surface alloys) with a Gaussian beam from a $3 \mathrm{~kW}$ continuous wave $\mathrm{CO}_{2}$ laser. While carrying out the treatments, the work-pieces were moved rather rapidly under the beam to create layer irradiated tracks (or passes) and a jet of argon gas was used to provide shielding during the treatments. The power density and the interaction time, controlled respectively through the diameter of the beam and the speed of movement of the work-piece, were so adjusted as to allow the melting (and mixing) of the powder as well as a thin layer of the base (i.e. pure iron). The details of the experiments are given below.

Three pieces of Armco iron (circular in cross-section, dia. $20 \mathrm{~mm}$, thickness $5 \mathrm{~mm}$ ) were coated with molybdenum powder, thickness of the layer of the powder on each piece being $150 \pm 50 \mu \mathrm{m}, 500 \pm 100 \mu \mathrm{m}$ and $1250 \pm 250 \mu \mathrm{m}$. On each sample, two tracks were then created by employing two different combinations of laser power and workpiece speed, these combinations being $2.35 \mathrm{~kW} / 15 \mathrm{~mm} / \mathrm{sec}$ and $1.7 \mathrm{~kW} / 8 \mathrm{~mm} / \mathrm{sec}$. To alloy the surface of pure iron with pure tin, a piece of Armco iron was laid with pure tin powder to a thickness of $500 \pm 100 \mu \mathrm{m}$ and then laser-treated. The $\mathrm{CW} \mathrm{CO}_{2}$ laser was operated at $1.6 \mathrm{~kW}$ and the work-piece speed during treatment was maintained at $15 \mathrm{~mm} \mathrm{~s}^{-1}$. In a similar manner, a piece of Armco iron laid with a mixture of 
molybdenum and tin powders to a thickness of approximately $300 \pm 50 \mu \mathrm{m}$ was treated to produce a pass on the surface. All the treatments described above were carried out using a beam of dia. $2.5 \mathrm{~mm}$. This beam diameter corresponds to an energy inpu' of $2.04 \times 10^{8} \mathrm{~J} \mathrm{~m}^{-2} \mathrm{~s}^{-1}$ per $\mathrm{kW}$ of laser power. Shielding to the area being laser-treated was provided by argon flowing through a jet at a rate of $11 / \mathrm{sec}$.

The pieces thus treated were cut, metallographically polished to $1 \mu \mathrm{m}$ diamond finish and chemically etched to reveal cross-sections of the melt track. Optical microscopy was employed to examine the structural features in the melt pool. The extent of dilution and the distribution of the alloying elements in the pool were investigated using a CAMEBAX electron probe microanalyser operating at an energy of $15 \mathrm{keV}$ and stabilized beam current of $100 \mathrm{nA}$. A LiF (lithium fluoride) crystal was used to diffract $\mathrm{K}_{\alpha}$ radiation of iron, and a PET (peniaerythritom) crystal was used to diffract the $\mathrm{L}_{\alpha}$ radiation of both molybdenum and tin. Microhardness $(25 \mathrm{~g})$ measurements as a function of depth from the laser-treated surface were made using a microhardness tester.

\section{Results}

The microstructure of the cross-section of the melt track created by a $\mathrm{CO}_{2}$ laser (power $1.7 \mathrm{~kW}$, speed $8 \mathrm{~mm} \mathrm{~s}^{-1}$ ) to alloy molybdenum in iron (molybdenum layer thickness $150 \pm 50 \mu \mathrm{m}$ ) is shown in figure 1. An enlarged view, obtained by scanning electron microscopy, is presented in figure 2. As shown in this micrograph, a thin rim at the bottom of the pool could be distinguished from the rest of the pool. Near

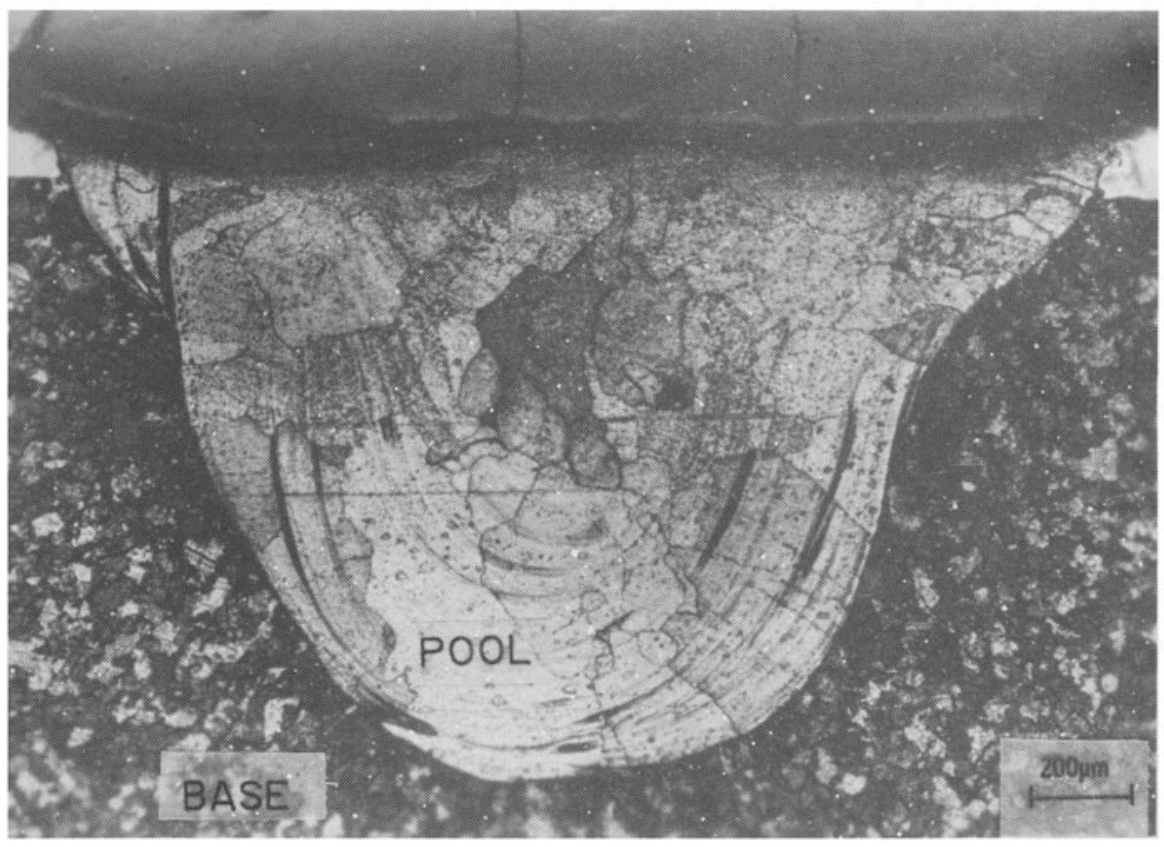

Figure 1. An optical micrograph of the cross-section of the melt track created to alloy iron by molybdenum; thickness of layer employed $150 \mu \mathrm{m}$. 




Figure 2. A secondary electron image of the cross-section of the melt track created to alloy iron by molybdenum.

the rim, in the pool, some clusters of particles couid be seen. A comparison of the cross-sections of the pools revealed that for a given thickness of the molybdenum layer the depth of the pool was larger when a combination of lower power density and larger interaction time was employed. Also, for a given combination of power density and interaction time, the top surface of the pool was found to be more and more concave and the frozen alloy that finally remained in the pool was found to be less and less with increasing thickness of the iayer employed. In our attempts to alloy tin in pure iron, or a combination of tin and molybdenum in pure iron, instead of an expected regular shape, isolated patches of the newly formed alloy were seen to be sticking to pure iron. Therefore it was difficult to reveal the microstructure in these cases.

For the case of alloying of iron by molybdenum employing a layer of thickness of $150 \pm 50 \mu \mathrm{m}$, the microhardness (measured along the centre line of the pool) is plotted in figure 3 as a function of distance from a point in the base. Whereas figure $3 \mathrm{a}$ is for a power of $1.7 \mathrm{~kW}$ and a work-piece speed of $8 \mathrm{~mm} \mathrm{~s}^{-1}$, figure $3 \mathrm{~b}$ is for a power of $2.35 \mathrm{~kW}$ and a work-piece speed of $15 \mathrm{~mm} \mathrm{~s}^{-1}$. The difference in the size of the two pools as well as their hardness is obvious. At the interface between the base and the melt-pool, the microhardness is seen to be falling rather slowly, in steps. Qualitatively similar results were obtained in the case of alloying of iron by tin, or a combination of molybdenum and tin. 

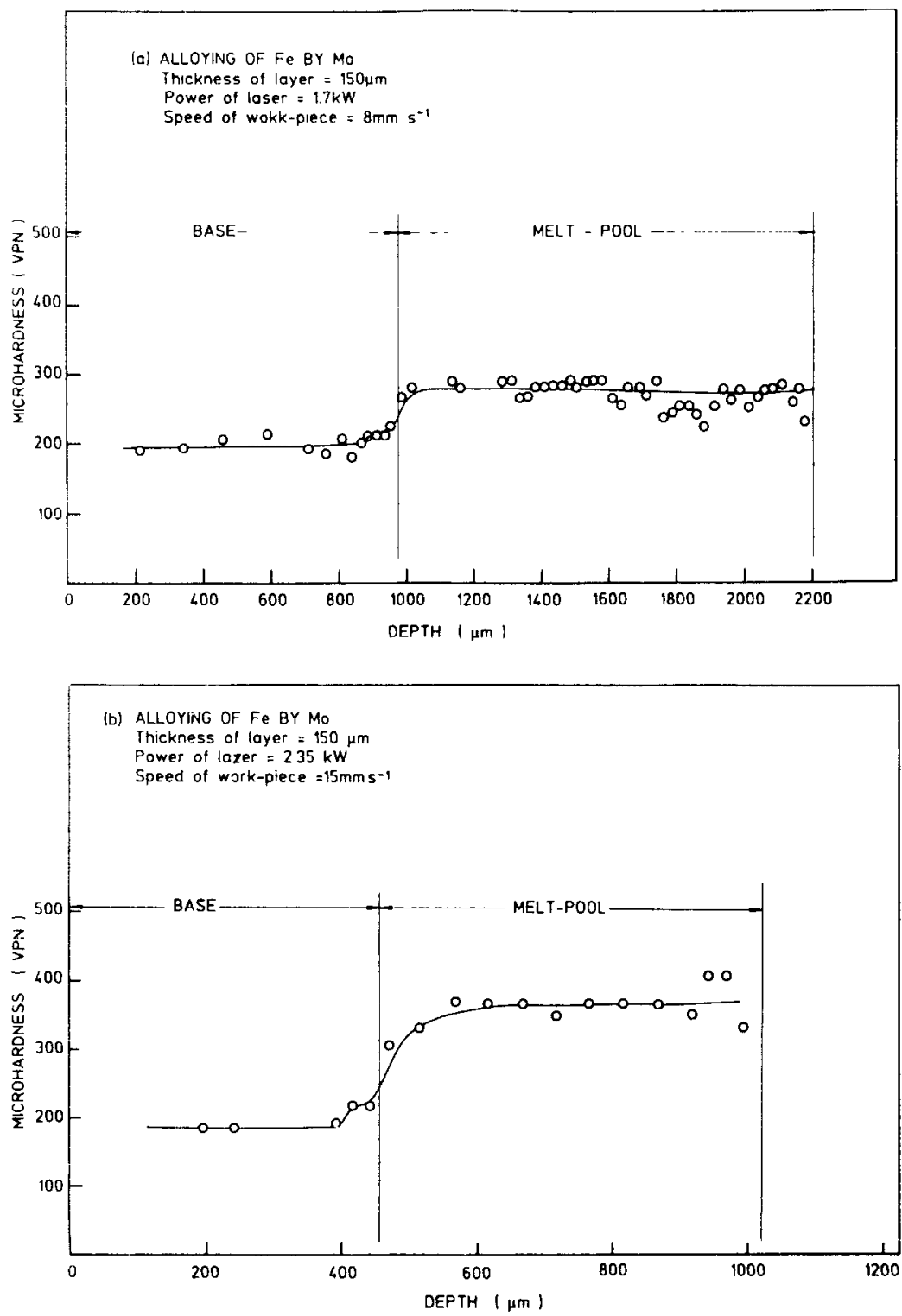

Figure 3. Microhardness (load, $25 \mathrm{~g}$ ) as a function of distance along the centre line of the pool for the case of alloying of iron by molybdenum using a layer of $150 \mu \mathrm{m}$; (a) power $1.7 \mathrm{~kW}$, speed $8 \mathrm{~mm} \mathrm{~s}^{-1}$; (b) power $2.35 \mathrm{~kW}$, speed $15 \mathrm{mms}^{-1}$.

Molybdenum and iron concentration profiles, obtained using an electron probe microanalyser, are exhibited in figures 4-7. In each figure, the thickness of the molybdenum layer and the parameters of the laser beam employed in the experiment are indicated. From a comparison of figures 4 and 5 , it is found that for a given thickness of a layer of molybdenum, the lower the laser power and the work-piece speed, the deeper is the pool and the lower is the molybdenum content in the alloy that solidifies. Also, for a given laser power and work-piece speed, the thicker the layer, the more the molybdenum level in the alloy that solidifies (figures 4,6 and 7). 


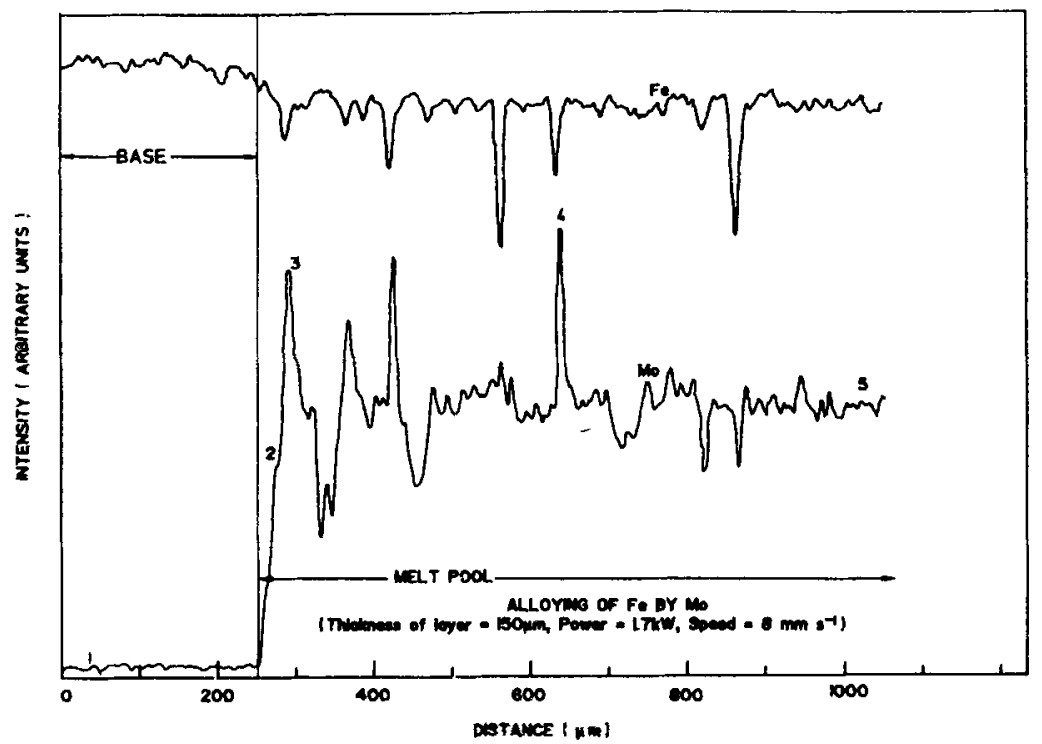

Figure 4. Molybdenum and iron concentration profiles across the melt pool and the base; alloying of iron by molybdenum (layer thickness $150 \mu \mathrm{m}$, power $1.7 \mathrm{~kW}$, speed $8 \mathrm{~mm} \mathrm{~s}^{-1}$ ).

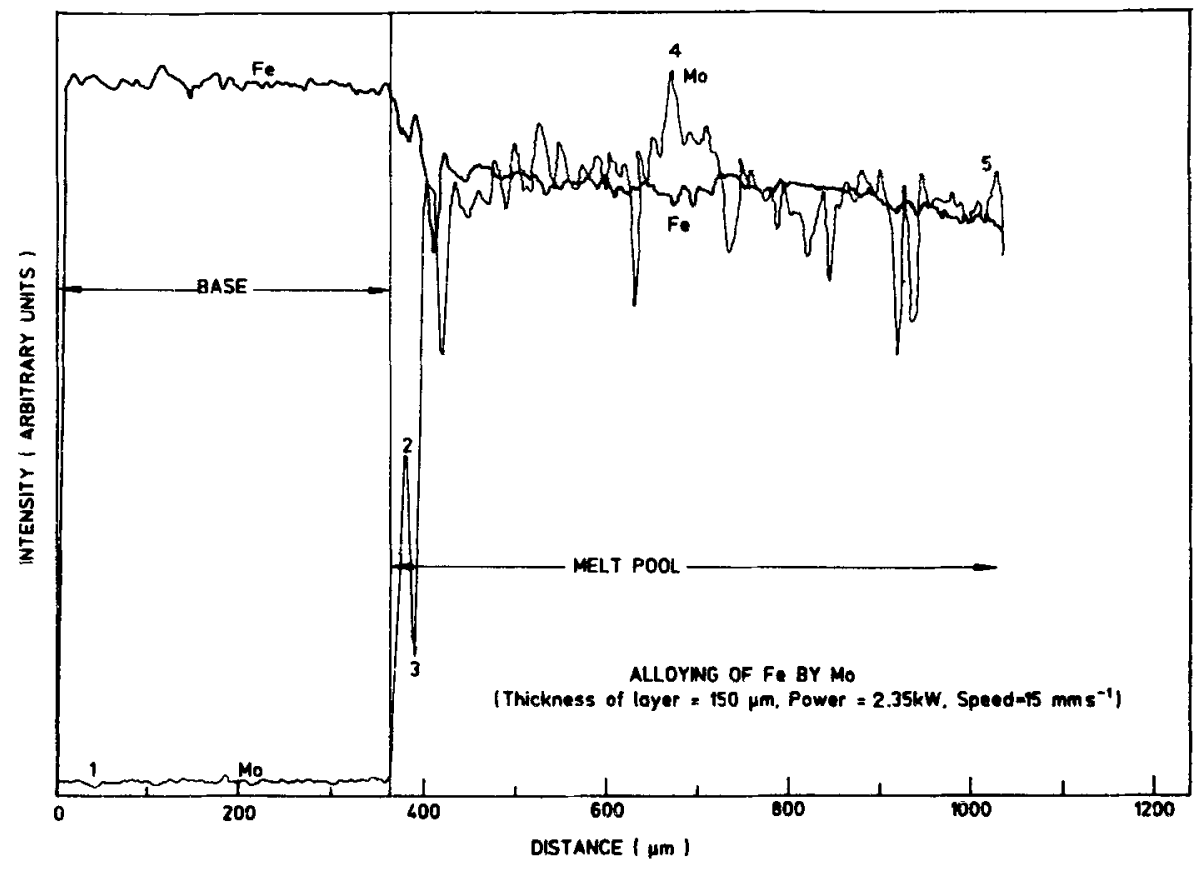

Figure 5. Molybdenum and iron concentration profiles across pool and the base; alloying of iron by molybdenum (layer thickness $150 \mu \mathrm{m}$, power $2.35 \mathrm{~kW}$, speed $15 \mathrm{~mm} \mathrm{~s}^{-1}$ ). 


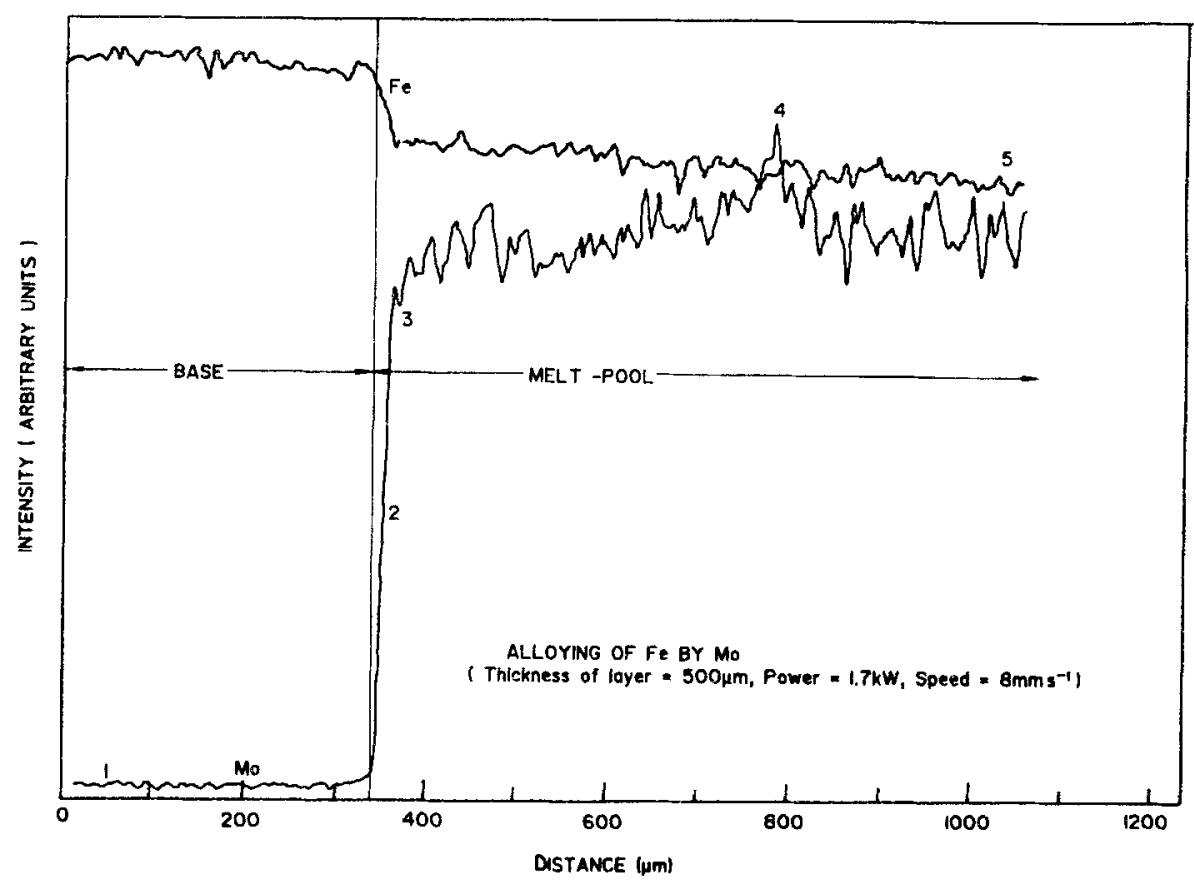

Figure 6. Molybdenum and iron concentration profiles across the melt base and the melt pool, alloying of iron by molybdenum (layer thickness $500 \mu \mathrm{m}$, power $1.7 \mathrm{~kW}$, speed $8 \mathrm{~mm} \mathrm{~s}^{-1}$ ).

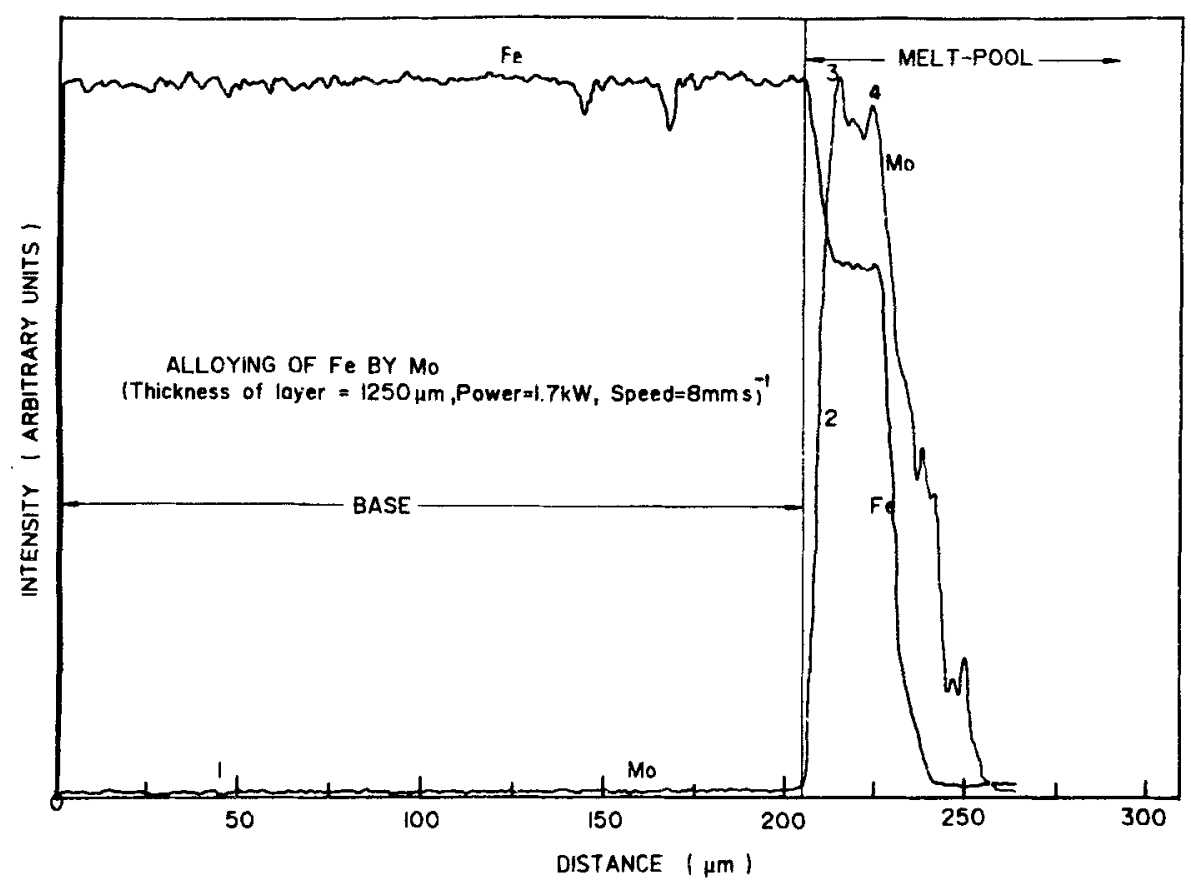

Figure 7. Molybdenum and iron concentration profiles across the base and the melt-pool; alloying of iron by molybdenum (layer thickness $1250 \mu \mathrm{m}$, power $1.7 \mathrm{~kW}$, speed $8 \mathrm{~mm} \mathrm{~s}^{-1}$ ). 
Table 1. Corrected concentrations at various locations (marked in the profiles of figures 4-7) in the melt pool and the base.

\begin{tabular}{|c|c|c|c|}
\hline \multirow[b]{2}{*}{ Figure } & \multirow[b]{2}{*}{ Point number } & \multicolumn{2}{|c|}{ Corrected composition (atom $\%$} \\
\hline & & Mo & $\mathrm{Fe}$ \\
\hline \multirow[t]{5}{*}{4} & 1 & $0 \cdot 1$ & $99 \cdot 9$ \\
\hline & 2 & $2 \cdot 3$ & $97 \cdot 7$ \\
\hline & 3 & 70 & $93 \cdot 0$ \\
\hline & 4 & 8.4 & 91.6 \\
\hline & 5 & $4 \cdot 6$ & $95 \cdot 4$ \\
\hline \multirow[t]{5}{*}{5} & 1 & $0 \cdot 1$ & $99 \cdot 9$ \\
\hline & 2 & $4 \cdot 4$ & $95 \cdot 6$ \\
\hline & 3 & $1 \cdot 7$ & $98 \cdot 3$ \\
\hline & 4 & $10 \cdot 1$ & $89 \cdot 9$ \\
\hline & 5 & 8.6 & 91.4 \\
\hline \multirow[t]{5}{*}{6} & 1 & $0-1$ & $99 \cdot 9$ \\
\hline & 2 & $2 \cdot 9$ & $97 \cdot 1$ \\
\hline & 3 & $6 \cdot 1$ & 93.9 \\
\hline & 4 & $8 \cdot 5$ & $91 \cdot 5$ \\
\hline & 5 & $7 \cdot 5$ & $92 \cdot 5$ \\
\hline \multirow[t]{4}{*}{7} & 1 & $0-1$ & 99.9 \\
\hline & 2 & $9 \cdot 8$ & $90 \cdot 2$ \\
\hline & 3 & 18.9 & $81 \cdot 1$ \\
\hline & 4 & $19 \cdot 2$ & 80.8 \\
\hline
\end{tabular}

The concentration profiles of iron and molybdenum shown in figures 4-7 indicate clearly the extent of mixing obtained by the laser treatment. The profiles exhibit a sharp interface followed by large compositional variations in the recast pool. It is also seen that the profiles of iron and molybdenum in each of these figures are complementary in nature. The compositions at various locations in the pool were evaluated from these profiles by employing the ZAF correction scheme (Bhanumurthy 1991). The results corresponding to various locations (marked in the profiles) in the base and the melt pool are listed in table 1. From these data it was found that the calculated compositions did not correspond to any of the known equilibrium intermetallic phases in the $\mathrm{Fe}-\mathrm{Mo}$ system. In the case of alloying of iron by tin, or a combination of molybdenum and tin, concentration profiles of the relevant elements indicated very large compositional variations from place to place in the pool. This perhaps indicates the presence of a number of phases in the recast structure.

\section{Discussion}

Surface alloying by a laser, apparently though just an extension of simple laser melting, involves some more complications. Though the complex interplay of various factors responsible for the solidification of the pool continues to be the same as in the case of simple laser melting, the factors responsible for the distribution (mixing) of the alloying elements during melting and subsequent solidification add to the complexity and take pre-eminence in any study of surface alloying. These factors are determined, apart from the nature of the alloying elements with respect to that of 
the base, by the parameters of the alloying experiments. In the present work, for a layer of Mo of $150 \mu \mathrm{m}$ thickness, pools of different depths were observed for the two different combinations of laser power and work-piece speed employed. For a power of $2.35 \mathrm{~kW}$ and a speed of $15 \mathrm{~mm} \mathrm{~s}^{-1}$, the maximum depth was $650 \mu \mathrm{m}$, and for a power of $1.7 \mathrm{~kW}$ and a speed of $8 \mathrm{~mm} \mathrm{~s}^{-1}$, the maximum depth was $1200 \mu \mathrm{m}$. These observations on the variation in the size of the pool as a function of power density/ interaction time for a given thickness of layer of molybdenum confirm the well established (Ready 1978; Rykalin et al 1988) fact that i; enough time is available for the heat being deposited by the laser beam to diffuse away into the work-piece, not only the pool is deeper but also the evaporation is less. The maximum temperature achieved at the surface depends on the difference between the rate at which the energy is put in by the laser and the rate at which it is extracted from the irradiated area by conduction through the work-piece. Because of this fact, a decrease in the power density coupled with an increase in the interaction time leads to a relatively lower surface temperature and less evaporation. Also, coarser microstructural features and an increase in the depth of the pool result (Mehrabian 1982). On the other hand, for a given combination of power density and interaction time, if the thickness of the layer is increased, a considerable amount of the alloying element (depending upon its vapour pressure) is lost by evaporation. This is because, for a given laser power and work-piece speed, an increase in the thickness of the coating of Mo powder (which, because of its porous nature, is a poor conductor of heat) results in a decrease in the rate at which heat is conducted away leading to an increase in the surface temperature. Also, the plasma resulting due to evaporation (if not removed quickly) hinders further input of energy to the work-piece. Due to these factors, the pool that results is shallower. Being thinner, it quenches rather rapidly leading to large quenching stresses and poor mixing. This explains the observations made on the shape of the top of the pool as a function of the thickness of the layer. Also the concentration profiles exhibited in figures 4-7 and the microhardness data in figure 3 are in agreement with this view. Tin, as compared to molybdenum, has a much lower melting temperature and does not wet iron. Also, if the same surface temperature is obtained as in the case of a layer of molybdenum on iron, tin would tend to boil off. (The boiling temperature of $\mathrm{Sn}$ is only $2270^{\circ} \mathrm{C}$ whereas the melting temperature of Mo is $2610^{\circ} \mathrm{C}$.) Moreover, the liquid of tin and that of iron are immiscible and form, by interdiffusion in the solid state, a number of intermetallic compounds. These factors are, perhaps, responsible for the severe compositional fluctuations in the patches of alloy that continue to stick to the base. A comparison of the results related to the alloying of Mo and $\mathrm{Sn}$ to Fe indicates that the nature of the intended alloying element in terms of its melting temperature with respect to that of the base, its viscosity and vapour pressure at the maximum surface temperature attained during the treatment, and considerations of mutual wettability and miscibility, in general, determine the extent of mixing that may be achieved in any laser alloying experiment. Similar considerations are adequate to explain the observations on the $\mathrm{Fe}-\mathrm{Sn}-\mathrm{Mo}$ system. However, in this ternary system there are more complications.

\section{Conclusions}

(i) For a given thickness of the layer of the intended alloying element, a combination of lower power density and larger interaction time results in a deeper pool. 
(ii) For a given power density and interaction time, larger the thickness of the layer, the higher is the surface temperature attained and larger is the evaporation. In such an event, the pool is thinner and, because of relatively faster cooling, poorer mixing results.

(iii) The nature of the intended alloying element with respect to that of the base metal determines the extent of mixing that may be achieved in any laser alloying experiment.

\section{Acknowledgements}

This work was carried out under the Indo-Soviet Long Term Programme (ILTP) of cooperation in the area of Laser Science and Technology. Laser treatments were carried out at the Baikov Institute of Metallurgy, Moscow, and characterization of the laser alloyed samples was carried out at BARC, Bombay, India. The authors are thankful to Dr S Banerjee, Head, Metallurgy Division, for his kind help. The authors are also grateful to the reviewers for their constructive comments to improve the scientific content of the paper.

\section{References}

Anthony T R and Clinen H E 1977 J. Appl. Phys. 483888

Bhanumurthy K 1991 Diffusion reactions in zirconium alloy systems, Ph. D. Thesis, Bombay University, Boinbay

Boettinger W J 1982 in Rapidly solidified amorphous and crystalline alloys; Proceedings of the Materials Research Society Annual Meeting, November 1981 (eds) B H Kear, B C Geissen and M Cohen (New York: North-Holland) p. 15

Chande T and Majumdar J 1979 in Applications of lasers in materials processing; Proceedings of $a$ Conference, April 1979 (ed) E A Metzbower (Metals Park, Ohio: ASM) p. 127

Crolet I L 1990 Acta Metall. 381547

Flemings M C and Shiohara Y 1984 Mater. Sci. Eng. 65157

Jones H 1984 Mater. Sci. Eng. 65145

Mehrabian R 1982 Int. Metals Rev. 27185

Molian P A, Wang P J, Khan K H and Wood W E 1982 in Rapidly solidified amorphous and crystalline alloys; Proceedings of the Materials Research Society Annual Meeting, November 1981 (eds) B H Kear, B C Geissen and M Cohen (New York: North Holland) p. 511

Metzbower E A 1981 in Source book on applications of the laser in metal working (ed) E A Metzbower (Metals Park, Ohio: ASM)

Nurminen J I and Smith J E 1979 in Applications of lasers in materials processing; Proceedings of a conference, (ed) E A Metzbower (Metals Park, Ohio: ASM) p. 94

Ready J F 1978 in Industrial applications of lasers (New York: Academic Press)

Rykalin N, Uglov A, Zuev I and Kakora A 1988 in Lasers and electron beam material processing (Moscow: Mir Publishers)

Porter D A and Easterling K E 1981 in Phase transformation in metals and alloys (New York: Van Nostrand) p. 317 and p. 384

Sarreal J A and Abbaschian G J 1986 Metals. Trans. A17 2063 